\title{
INFANTILE AUTISM AND 47,XYY KARYOTYPE
}

\author{
Evelyn Kuczynski', Débora Romeo Bertola ${ }^{2}$, Cláudia Irene Emílio de Castro', \\ Célia Priszkulnik Koiffmann ${ }^{3}$, Chong A. Kim²
}

There is growing evidence that genetic and chromosomal factors are important in the genesis of autism spectrum disorders. The most commonly reported cytogenetic abnormalities are deletions involving chromosomes $7 q$, 22q13, 2q37, 18q, and Xp, as well as sex chromosome aneuplodies (47,XYY and 45,X/46,XY mosaicism)'. Sex chromosomes seem to be of major importance in the genesis of some cases of autism².

We report an adolescent with a diagnosis of infantile autism, in which genetic investigation disclosed the 47 , XYY karyotype (also known as "double Y"). Informed consent was obtained with the patient's parents.

\section{CASE}

A male first-born of healthy, non-related parents, whose prenatal and perinatal exams were unremarkable. As from 30 months of age, the patient presented an important impairment in social skills development and received a diagnosis of pervasive developmental disorder (PDD), infantile autism. At 7 years of age, an accelerated growth in height was evident. The patient was evaluated initially at 12.5 years-old, presenting weight in the $90^{\text {th }}$ centile, height above $97.5^{\text {th }}$ centile, and normal cephalic perimeter. Physical examination also disclosed brachicephaly, discretely elongated facial features, thickened eyebrows, anteriorized earlobes, thoracic asymmetry, marfanoid "habitus" and long fingers. Psychic examination disclosed a puerile attitude, somewhat disinhibited for age and context, good verbal development (use of vocabulary and highly elaborated grammatical constructions incompatible with the patient's age and global cognitive performance), fulfilling DSM-IV-TR diagnostic criteria for IA, since he had qualitative deficits on social engagement and adaptation, communication and imagination. His presentation did not fulfilled diagnostic criteria for Asperger disorder since he did not show encompassing preoccupation with one or more stereotyped patterns of interests, abnormal either in intensity or focus, nor presented inflexible adherence to specific, nonfunctional routines and rituals. He also had (reviewing his past development) general delay on language acquisition dur- ing early childhood ${ }^{3}$. Childhood Autism Rating Scale (CARS) application showed a score of 31, compatible with mild/moderate autism ${ }^{4}$, and application of Escala de Avaliação de Traços Autísticos (ATA) showed 22, positive for IA $\mathrm{A}^{5}$. Vineland Adaptive Behavior Scale ${ }^{6}$ was applied, presenting a score of 76 , compatible with average adaptive performance for his age. A complementary echocardiogram showed discrete pulmonary insufficiency. Homocistinuria test was negative, and an ophthalmologic evaluation was normal. Chromosome study of the patient was performed in cultivated peripheral blood lymphocytes, using the GTG-banding technique and a 47,XYY karyotype was disclosed. Fluorescence in situ hybridization (FISH) with whole human chromosome $Y$ paint (WCP) confirmed the presence of two $Y$ chromosomes in 20 analyzed metaphases.

\section{DISCUSSION}

The presence of a 47,XYY karyotype in boys with pervasive developmental disorders (PDD) has rarely been described ${ }^{7}$. However, there are several single case studies in the literature of autism spectrum disorders in connection with the XYY syndrome ${ }^{2,7}$. In the last decade there has been a significant increase in the proportion of XYY males detected prenatally, mostly as a fortuitous finding. These patients are at considerably increased risk for delayed language and/or motor development, and from primary school age on, there is an increased risk for child psychiatric disorders such as autism ${ }^{8}$. An extra $Y$ chromosome may be related to abnormal brain development, which may, in turn, predispose vulnerable males to PDD ${ }^{7}$. In a clinic for children with developmental disorders, two of 40 male referrals had 47,XYY karyotypes, finding that suggest the rate of this sex chromosome anomaly may be increased in PDD ${ }^{7}$. Otherwise, Weidmer-Mikhail et al. ${ }^{9}$ found a double $Y$ in a consecutive series of 75 male children with PDD, and proposed that such chromosomal abnormalities are uncommon in traditional autism and may be relatively more common in people with PDD not otherwise specified. Our case report corroborates those de-

\footnotetext{
AUTISMO INFANTIL E CARIÓTIPO 47,XYY

${ }^{1}$ Instituto de Psiquiatria do Hospital das Clínicas da Faculdade de Medicina da Universidade de São Paulo, São Paulo SP, Brazil; ${ }^{2}$ Unidade de Genética do Instituto da Criança do Hospital das Clínicas da Faculdade de Medicina da Universidade de São Paulo, São Paulo SP, Brazil; ${ }^{3}$ Departamento de Genética e Biologia Evolutiva do Instituto de Biociências da Universidade de São Paulo, São Paulo SP, Brazil.
} 
scribed in the medical literature and rephrases the importance of chromosomal studies to be done in cases within the group of autism spectrum disorders'.

\section{REFERENCES}

1. Mendelsohn NJ, Schaefer GB. Genetic evaluation of autism. Semin Pediatr Neurol 2008;15:27-31.

2. Gillberg C, Winnergard I, Wahlström J. The sex chromosomes: one key to autism? An XYY case of infantile autism. Appl Res Ment Retard 1984;5:353-360.

3. APA (American Psychiatric Association). Diagnostic and statistical manual of mental disorders, Fourth Edition, Text Revised. Washington, DC: American Psychiatric Publishing Inc, 2000.

4. Pereira AM. Autismo infantil: tradução e validação da CARS (Child- hood Autism Rating Scale) para uso no Brasil [dissertação]. Porto Alegre: Universidade Federal do Rio Grande do Sul, 2007.

5. Assumpção FB Jr, Kuczynski E, Rego MGS, Rocca CCA. Escala de avaliação de traços autísticos (ATA): validade e confiabilidade de uma escala para a detecção de condutas autísticas. Arq Neuropsiquiatr 1999;57: 23-29.

6. Sparrow SS, Balla DA, Cicchetti DV. Vineland adaptive behavior scales. Circle Press. MN: American Guidance Service, 1984.

7. Nicolson R, Bhalerao S, Sloman L. 47,XYY karyotypes and pervasive developmental disorders. Can J Psychiatry 1998;43:619-622.

8. Geerts M, Steyaert J, Fryns JP. The XYY syndrome: a follow-up study on 38 boys. Genet Couns 2003;14:267-279.

9. Weidmer-Mikhail E, Sheldon S, Ghaziuddin M. Chromosomes in autism and related pervasive developmental disorders: a cytogenetic study. J Intellect Disabil Res 1998;42:8-12 